\title{
Complementary Medicine Provision in an Academic Hospital: Evaluation and Structuring Project
}

\author{
Pierre-Yves Rodondi, MD, ${ }^{1,2}$ Emmanuelle Lüthi, MSc, ${ }^{2,3}$ Julie Dubois, MA, ${ }^{1,2}$ \\ Edith Roy, RN, Bernard Burnand, MD, MPH, and Geneviève Grass, MScN ${ }^{1}$
}

\begin{abstract}
Objectives: Complementary medicine (CM) has become increasingly available in hospital settings in several countries. Nonetheless, there are disparities in the provision and organization of CM between hospitals and even within a single hospital. This was the case at Lausanne University Hospital, where neither a registry of CM practices nor homogeneous guidelines for the provision of $\mathrm{CM}$ existed. The board of directors mandated the use of an internal consultant to assess practices, delineate the ward's needs, and draft proposals to structure the provision of CM services.

Design: Lescarbeau et al.'s integrated model of consultation was used.

Settings/Location: Academic medical center, Switzerland.

Subjects: Heads of departments, medical and nurse directors, and CM practitioners.

Interventions: Semi-structured interviews, online survey, and focus groups were used to focus on CM availability, needs, and practices; CM practitioner background, training, and position in the hospital; and the type of patients treated.

Results: The assessment identified 15 types of $\mathrm{CM}$ in 51 wards, provided by $\mathrm{CM}$ practitioners who represented the profiles of 8 types of health care professionals. Three barriers to implementing CM were identified: heterogeneity in CM practitioners' training and project implementation, lack of CM information for patients and health care professionals, and variable access to CM among hospital wards and resulting lack in continuity of care. Three main needs regarding CM were delineated: to ensure CM quality, to provide structured interdepartmental CM clinical services, and to provide CM information to patients and health care professionals. Three action priorities were selected by the board of directors: to develop structured CM clinical services; to select $\mathrm{CM}$ provision based on the specific criteria of scientific evidence, therapies already available at hospital, and specific ward's needs; and to provide CM information to patients and health care professionals.
\end{abstract}

Conclusions: This assessment permitted to structure CM provision according to internal consultation.

Keywords: complementary medicine, integrative medicine, hospital settings, academic hospital

\section{Introduction}

Complementary medicine (CM) has become increasingly available in hospital settings in several regions, including the United States, ${ }^{1}$ Canada, ${ }^{2}$ Australia, ${ }^{3}$ and Europe, ${ }^{4,5}$ including Switzerland. ${ }^{6,7}$ Evidence of the effectiveness of CM interventions for specific health problems is growing, includ- ing that reported in systematic reviews and meta-analyses. ${ }^{8-10}$ For example, CM could be useful for reducing pain and anxiety after cardiac surgery, ${ }^{11}$ or for reducing pain, anxiety, and opioid use after major burns. ${ }^{12}$

At Lausanne University Hospital, CM research and teaching activities, provided by the Center for Integrative and Complementary Medicine (CEMIC), were implemented in 2010.

\footnotetext{
${ }^{1}$ Center for Primary Care and Public Health (Unisanté), University of Lausanne, Lausanne, Switzerland.

${ }^{2}$ Institute of Family Medicine, University of Fribourg, Fribourg, Switzerland.

${ }^{3}$ Department of Anesthesiology, Center for Integrative and Complementary Medicine, Pain Center, Lausanne University Hospital, Lausanne, Switzerland.
} 
The CEMIC, created by the board of directors, is the center of expertise on CM and is part of this public academic hospital. At the time of this project, it had no clinical activity. Before this assessment, CM services were implemented in this hospital, although they were not consistently applied across wards. Neither quality standards for CM practitioners and CM therapies nor coordinated CM services existed. For example, access to $\mathrm{CM}$ therapies for similar health problems was not equally available among the wards, leading to treatment cessation when a patient moved from one ward to another.

For these reasons, CM needed to be organized, controlled, and coordinated within the hospital. Therefore, the board of directors mandated CEMIC to conduct the present project to meet three objectives: assess current practices, delineate the needs of wards, and draft proposals to structure the provision of CM.

\section{Materials and Methods}

\section{Design}

The integrated model of consultation developed by Lescarbeau et al. ${ }^{13}$ was favored in this project. This model is of great interest when an assessment of current practices-here $\mathrm{CM}$ practices in the hospital-is mandated. It favors the mobilization of human resources as well as the cooperation between all the actors involved in the project. The consultant considers that the actors in the field are experts and provide them with support through a rigorous methodology. This model consists of six steps: opening, agreement, orientation, planning, achievement, and termination (Fig. 1). The first three steps have been completed in this project.

During the opening, the consultant (CEMIC) and the client (board of directors) exchanged information to accurately describe the initial situation and to decide on the relevance of the project. In the second step, called the agreement, both parties collaborated to come to a clear and specific agreement to move from the initial to the desired situation and to define the investigation's process. In this project, the initial situation was the lack of information about the provision of CM in the hospital, as well as its lack of homogeneity. The desired situation was a more structured provision of $\mathrm{CM}$ within the hospital. Thus, the agreement was to assess current practices and to produce recommendations to choose action priorities. The third step labeled orientation was the time to collect information and analyze the data to move toward the desired situation.

\section{Setting and location}

The project was undertaken in Lausanne University Hospital (CHUV), an academic medical center offering over 1,500 beds in 12 departments. In 2016, about 50,000 patients were hospitalized. This project was conducted from December 2015 to June 2016.

\section{Subjects}

The heads and CM practitioners of the 12 departments and the medical and nurse directors were interviewed. As no registry was available, a snowball sampling technique ${ }^{14}$ was used to identify CM practitioners within the hospital.

\section{Interventions}

Individual semi-structured interviews were conducted with medical and nurse directors and group semi-structured interviews with the 12 department heads. Questions focused on CM availability and needs in departments, as well as access to reliable CM information and interdepartmental CM clinical services. Besides, structured interviews, with four open-ended questions at the end, were conducted either face-to-face or by phone with CM practitioners. These questions addressed the following: CM practices; practitioner background, training,

TOP

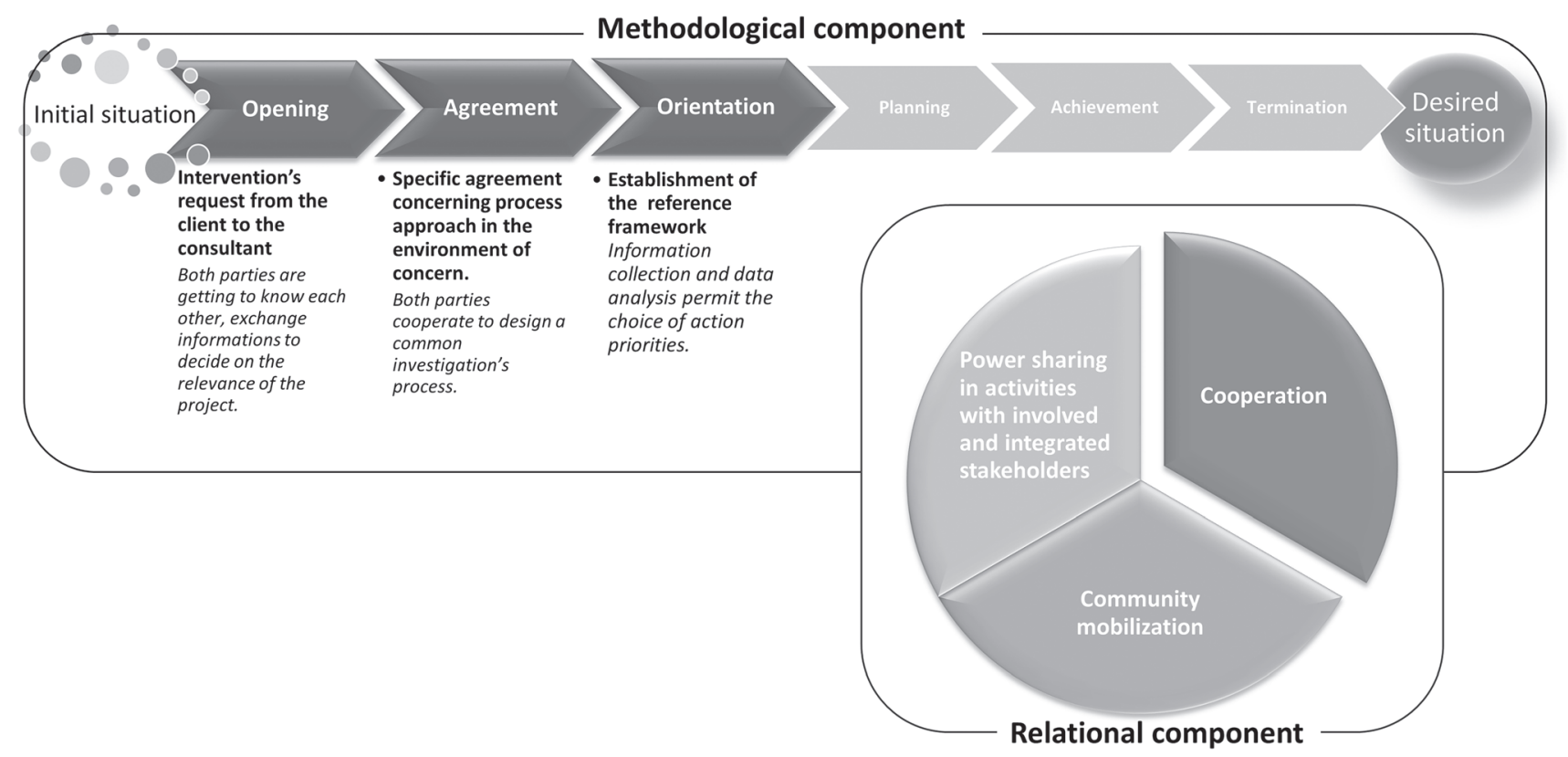

FIG. 1. Schema of the integrated model of consultation developed by Lescarbeau et al. ${ }^{13}$ 
and financial sources; private practice and insurance reimbursement; practitioner position in the hospital; time dedicated to $\mathrm{CM}$ practice in the hospital; type of patients treated; $\mathrm{CM}$ information sources used by patients and health care professionals; and the means used to guarantee care traceability. Open-ended questions focused on CM project implementation, patient feedback, the need to maintain and improve $\mathrm{CM}$ practice, and opening of CM practice to patients from different wards. The duration of these interviews ranged from 30 to $60 \mathrm{~min}$. In the psychiatry department, two further instruments were used. As this department is divided into different distant locations, an online survey was sent to each hospital ward's nurse manager who addressed questions about $\mathrm{CM}$ provision in the department and the practitioner's position in the hospital.

All notes taken during interviews were transcribed, and descriptive content analysis was performed manually. Interviews were coded by two researchers, and the codes were then grouped into categories and the categories into themes. The analysis highlighted three distinct categories: CM practices, barriers, and needs.

\section{Results}

\section{Assessment of current practices}

A total of 15 types of $\mathrm{CM}$ were identified that were provided in 51 hospital wards (Fig. 2) by CM practitioners representing 8 health care professional profiles, mostly nurses and physiotherapists. Only a few CM practitioners had no conventional health care background (Table 1). Hypnosis and massage were the most frequent CMs provided in hospital wards (Fig. 2). The psychiatry department offered the largest number of $\mathrm{CM}$ provisions, whereas the oncology department offered no provisions. The training and qualifications of CM practitioners were not subjected to structured control. Indeed, for the same CM, the training duration ranged from a few days to several years. Symptoms such as pain, anxiety, and insomnia or when conventional medicine reached its limits were the health care professionals' principal motivations to ask for a CM intervention.

Projects to implement $\mathrm{CM}$ in a ward were developed when health care professionals proposed applying their CM training or when hospital ward heads supported the training of health care professionals to further introduce a CM. Some projects were informally introduced, such as massage and reiki in internal medicine wards, whereas others, such as acupuncture in the pain center and hypnosis in the burn center, received approval by the board of directors.

Some CMs were carried out by health care professionals during regular working hours if they had sufficient time, whereas other CMs were offered during dedicated time. Only a few health care professionals were employed exclusively for $\mathrm{CM}$. Some CM-trained health care professionals did not obtain specific CM dedicated time due to lack of funding. Offers were mainly assigned to a single department, or even to a single ward. CMs were generally provided to patients for specific health problems, in either outpatient or inpatient settings, but continuity of care was not always guaranteed (e.g., when CM practitioners were on vacation). Furthermore, positive feedback from patients and health care professionals was the main motivation for $\mathrm{CM}$ practitioners to maintain $\mathrm{CM}$ provision.

Notes related to CM therapies were mostly documented in patient files. However, they were stored in different locations since no specific locations were developed within the system. In some cases, no note was provided.

\section{Barriers to implementing $\mathrm{CM}$}

Three barriers to implementing CM were identified. First, $\mathrm{CM}$ practitioner training and project implementation was inconsistent, as there was no recommendation for institutional CM practices in the hospital. Second, information on $\mathrm{CM}$ was lacking for patients and health care professionals. Third, access to CM was variable among hospital wards, resulting in a lack in continuity of care. Although CMs were recommended in some facilities, they were discouraged for patients with similar health problems in other wards. Moreover, since some CMs were not covered by mandatory basic health insurance or supplemental health insurance, access was not granted to all patients. Furthermore, some CMs were discontinued because a CM practitioner quitted without being replaced, a new manager decided to stop offering them, or a private donator stopped funding them.

\section{Needs regarding CM provision and practitioners}

Three topics regarding the needs of hospital wards and CM practitioners were discussed during the interviews. The first
FIG. 2. Number of wards providing $\mathrm{CM}$ by type of CM. CM, complementary medicine.

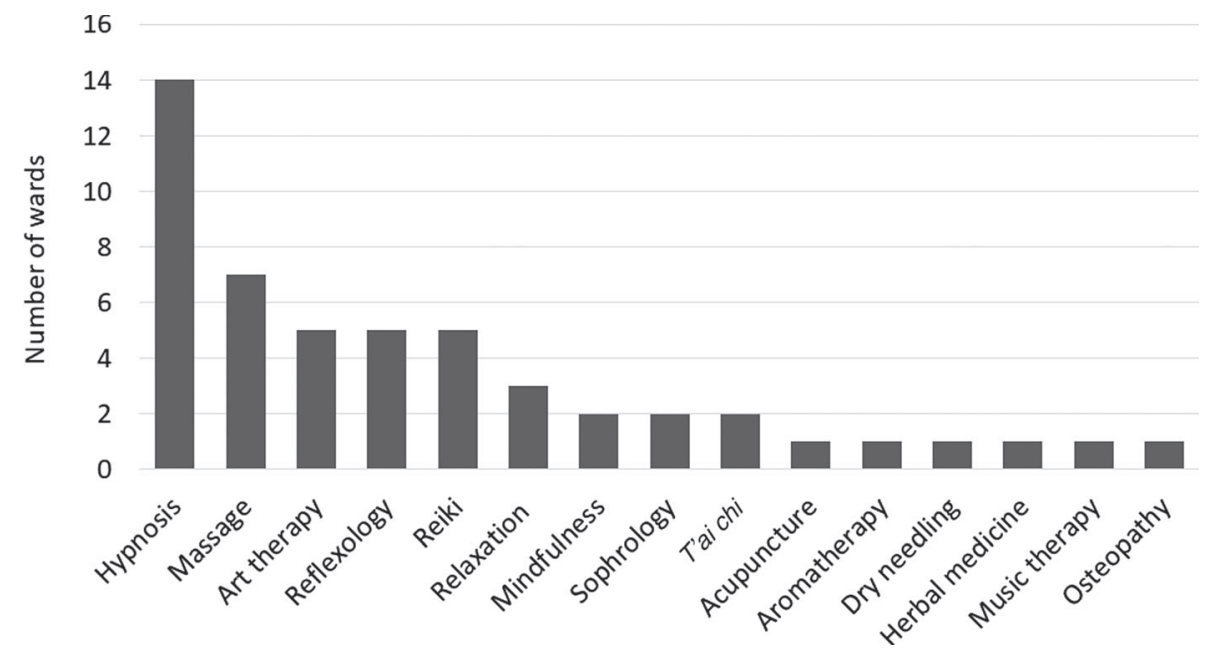


Table 1. Health Care Professional's Profile of Complementary Medicine Practitioners

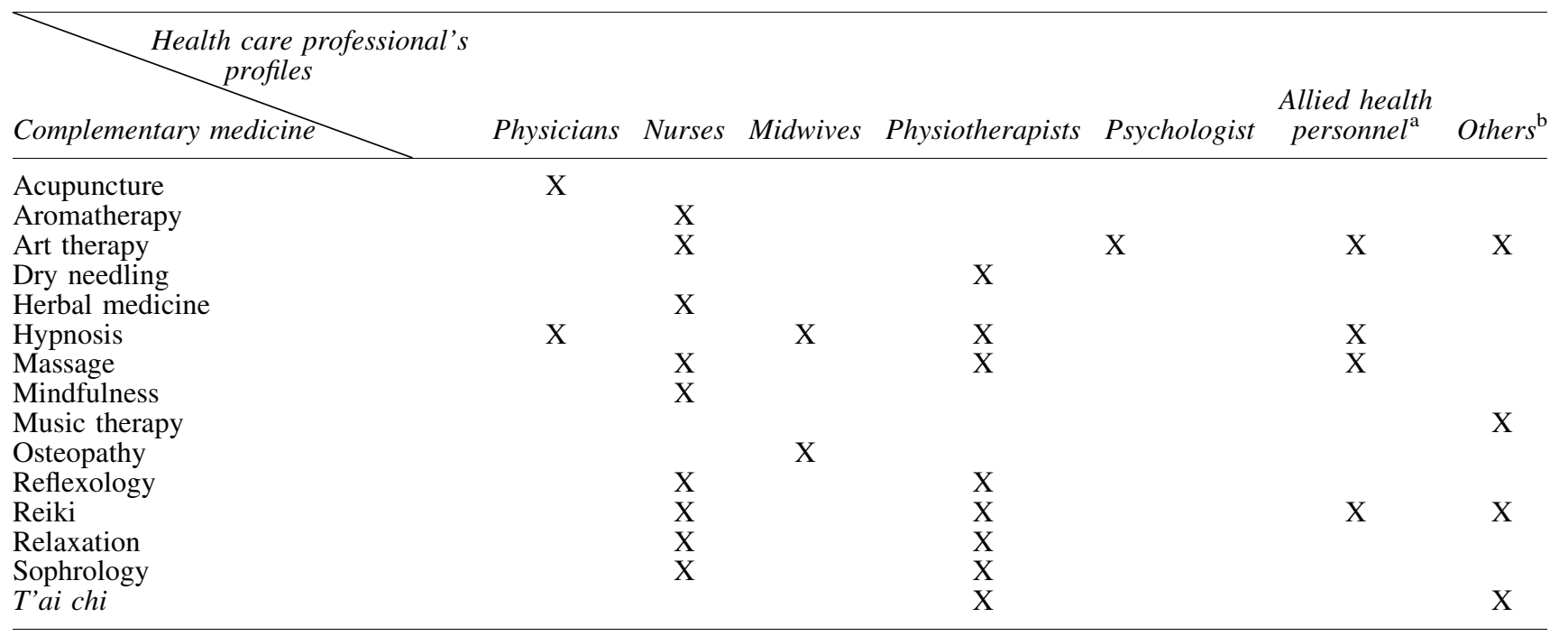

${ }^{\mathrm{a}}$ Health care assistant, care assistant.

${ }^{\mathrm{b}}$ Artists, music educators, volunteer, t'ai chi teacher.

concerned CM quality. Some CM practitioners expressed the need for support by CEMIC to concretize and achieve their project or to assess its pertinence. CM practitioners, department heads, and medical and nurse directors agreed on the importance of continuous CM training, evaluation, and research. The creation of a comprehensive registry of CM practitioners, including training information, was suggested as a way to ensure quality. The need to define the specific role of CM practitioners in a formally written manner was further expressed. To ensure continuity of care, department heads, medical and nurse directors, and practitioners also stressed the importance of $\mathrm{CM}$ documentation in a standardized patient file.

The second need pertained to the provision of structured CM clinical services. All department heads agreed on providing only a limited number of CMs for specific health problems, supported by scientific evidence. According to department heads, some CMs, such as acupuncture in the delivery room, should be available day and night, 7 days a week, and provided by trained health care professionals working in the hospital.

The third need concerned CM information. The creation of a website for patients and health care professionals with CM recommendations, herb-drug interactions, and scientific articles about CM effectiveness seemed to be important to the department heads. CM practitioners believed that it would be helpful to better inform patients and health care professionals about their CM provisions. This information could add value to their work and help them to be better recognized by their colleagues.

\section{Proposals for more structured CM health care services}

In accordance with the methodology and objectives of this project, the consultant synthesized the resulting data and provided a written report to the board of directors containing

Table 2. Barriers to Implementing Complementary Medicine and Proposals for More Structured Complementary Medicine Health Care Services

Barriers to implementing $C M$

Proposals for more structured CM health care services

Inconsistency of CM practitioner training and project implementation, and absence of recommendation for CM practices in the hospital.

Lack of information on CM for patients and health care professionals.

Variable access to $\mathrm{CM}$ among hospital wards, resulting in a lack in continuity of care.
1. Choose $\mathrm{CM}$ provision based on the specific criteria of scientific evidence, therapies already available at the hospital, and the specific needs of wards.

2. Define required training for $\mathrm{CM}$ practitioners and develop an official register of CM practitioners active in the hospital.

3. Provide information about CM to patients and health care professionals by developing a website and flyers.

4. Develop structured interdepartmental CM clinical services for specific health problems, as medically prescribed by certified CM practitioners.

5. Create a common standardized form in the computerized medical record to ensure traceability of care and follow-up of care indicators.

6. Assess CM costs and reimbursement possibilities to ensure equity of access to CM.

$\mathrm{CM}$, complementary medicine. 
six proposals to move toward the desired situation (Table 2). Of the proposals described in Table 2, the board of directors selected points 1,3 , and 4 as action priorities to structure $\mathrm{CM}$ within the hospital. Selection of priorities was based on measures that could increase the security of patients and could be implemented in a short time. Furthermore, these priorities met the needs of wards identified in this project: consistent and evidence-based CM, information on CM for both health care professionals and patients, and fair access to CM.

\section{Discussion}

The aim of this project was to better understand and map out $\mathrm{CM}$ provision at an academic hospital. Fifteen types of $\mathrm{CM}$ were identified and provided in 51 hospital wards. Hypnosis and massage were the main CMs provided. Training, work time, and project development processes were highly heterogeneous across the hospital.

\section{Assessment of current practice}

In this project, $\mathrm{CM}$ was mostly provided by nurses and physiotherapists, in line with another study showing that, in $2006,37 \%$ of Swiss CM providers in hospitals were physicians, whereas $64 \%$ were therapists or nurses. ${ }^{6} \mathrm{CM}$ practitioners having a health care professional background is a common feature among hospitals proposing CM. ${ }^{4,15-17}$ This background could facilitate the integration of CM practitioners. ${ }^{17,18}$

Some of the $15 \mathrm{CMs}$ reported in this project were also reported in other Swiss hospitals, including osteopathy, ${ }^{7}$ hypnosis, ${ }^{7}$ and acupuncture. ${ }^{6,7}$ Other CMs reported in other hospitals but not in this project were anthroposophic medicine ${ }^{6}$ and homeopathy. ${ }^{6,19}$ This shows that CM provision differs from one hospital to the next, probably more so than occurs with the provision of conventional medicine. Some therapies, such as massage and hypnosis, were not always considered CMs in other studies and could have been underreported.

In this project, the oncology department offered no CMs. This finding seems to contradict other studies that reported the largest number of CM provisions in oncology departments. ${ }^{4,20-27}$

The main motivations to provide and maintain $\mathrm{CM}$ in this project were symptoms such as pain, anxiety, or insomnia; difficult care situations; and positive feedback from patients and health care professionals. In other settings, reasons to deliver CM included pain, anxiety, ${ }^{4,28}$ prevention of drugrelated side effects, ${ }^{4,28}$ scientific evidence for some CMs, ${ }^{4,29}$ management of chronic diseases, ${ }^{2,28}$ patient or employee requests, ${ }^{4,7,28}$ long hospitalizations, ${ }^{28}$ or patients not responding to conventional medicine. ${ }^{4,28}$

Processes for CM implementation were heterogeneous. A Swiss study previously reported that procedures for introducing CM in hospitals were disparate. ${ }^{7}$ That study also emphasized that CM introduction could be facilitated if a physician promoted the project to the board of directors. A recurrent theme in the literature is the leading role of a physician, often specialized in $\mathrm{CM}$, in facilitating the implementation of $\mathrm{CM}$ and supporting it among conventional physicians. ${ }^{2,16,17,30}$ However, conventional physicians often remain reluctant or skeptical regarding CM. ${ }^{17,20}$ One reason for this could be the lack of knowledge about $\mathrm{CM}^{25}$ and minimal exposure to it during medical training. ${ }^{31}$ Moreover, the general lack of scientific evidence about the efficacy of CMs could be another drawback, despite growing evidence for specific CMs. ${ }^{20}$
Our survey showed that some CMs were provided by health care professionals during regular working time while other health care professionals had specific contracts. This situation is similar to that of other Swiss hospitals. ${ }^{7}$ This inconsistency in contract type and working time devoted to CM could lead to a situation reported by a Canadian study, which stressed that hospitals hid the time spent by $\mathrm{CM}$ practitioners behind general hospital practice. ${ }^{2}$ Moreover, our results showed that some health care professionals provided CM only if they had sufficient time. In some hospitals, this lack of dedicated CM time could lead to $\mathrm{CM}$ practitioners having to prioritize patients because of the imbalance between $\mathrm{CM}$ requests and practitioners' availability. ${ }^{18}$

\section{Barriers, needs, and proposals to implement CM}

The results of this project emphasized the heterogeneity of $\mathrm{CM}$ practitioner training. Indeed, training qualifications were not subjected to structured control, unlike other integrative medicine projects, which assigned high importance to the training evaluation of practitioners. ${ }^{23,32,33}$ Therefore, institutional standardization of training requirements should be required to ensure quality and safety of care. Thus, requirements of training for each CM would be specified by a working group of physicians, nurses, and human resources staff. Moreover, considering the high prevalence of severe diseases in a hospital setting, it was decided during this project that CM therapists had to be trained in an official health care profession.

Regarding the heterogeneity of project implementation by $\mathrm{CM}$ practitioners, our results showed that the provision of $\mathrm{CM}$ ended for organizational reasons. To address this issue, some institutions openly institutionalized $\mathrm{CM}$ through a process of monitoring and measurement of results. ${ }^{7}$ Thus, the CM modality was no longer related to and dependent on a specific practitioner but had been accepted, allowing sustainability of practice. Project implementation also relates to the choice of CM. As has been suggested by others, ${ }^{25,34}$ this project proposed to select CMs on the basis of specific criteria, including scientific evidence. In Switzerland, homeopathy, Traditional Chinese Medicine, anthroposophic medicine, and herbal medicine are the four CMs delivered by physicians who require specific training and meet federal standards. For nonphysicians, there is a wide range of training and of legal status, which also differs between cantons. Thus, local regulation is one-but not the only-element to consider in choosing which CM could be delivered within the hospital.

The second barrier-lack of CM information and need for support to ensure quality of care-could be resolved by building a common philosophy of values and beliefs for the management of patient care in the institutional culture. . $^{1,31}$ Indeed, the quality and level of communication among physicians and between physicians and patients could be affected if all treatment options external to the physician discipline are not considered. ${ }^{35}$ Therefore, we avoided the terminology "integrative medicine" in this project because in this hospital, conventional medicine and CM still needed to be organized "in a coordinated way" as mentioned in the National Center for Complementary and Integrative Health definition. ${ }^{36}$ However, integrative medicine is what should be provided in hospitals, especially in academic centers. Some studies have suggested improving CM literacy and education among hospital health care professionals ${ }^{34}$ and 
promoting the access of physicians to relevant evidencebased studies to enhance their CM knowledge and increase their willingness to advocate $\mathrm{CM}$ in certain situations. In addition, recent programs have been developed to improve $\mathrm{CM}$ in oncology settings. ${ }^{37-39}$

The third barrier, variable access to $\mathrm{CM}$ at this hospital, was in part based on the fact that some CMs were not covered by mandatory basic health insurance. Indeed, in 2006, 58\% of CM costs in Swiss hospitals were covered by mandatory basic health insurance, $28 \%$ by complementary health insurance, and $9 \%$ directly by patients. ${ }^{6}$ Currently in Switzerland, the mandatory basic health insurance reimburses anthroposophic medicine, herbal medicine, homeopathy, and Traditional Chinese Medicine when performed by certified physicians. ${ }^{7}$ According to Grant et al., ${ }^{40}$ costs are identified as a barrier to CM integration. Furthermore, in this hospital, CMs were provided only in specific departments, leading to a lack of continuity of care for CM. One way to ensure this continuity of care in a hospital is to guarantee a written record of CM treatments in the main electronic medical record (EMR). ${ }^{7,29,33,41}$ The results of this project showed a need for better documentation of CM treatments because notes on $\mathrm{CM}$ were not systematically recorded in the patients' EMRs, as has also been the case in other settings, ${ }^{42}$ despite the fact that sharing of patients' medical information in the EMR has been shown to be vital. ${ }^{40}$

\section{Action priorities to structure CM}

The board of directors of the hospital decided to develop CM clinical services as a priority. To test its feasibility, a pilot project in the oncology department was set up to develop a CM team, ensuring quality and traceability of care and providing counseling and information for patients and health care professionals. The oncology department was chosen for this pilot project-which will be carried on until the end of 2019-for four reasons: frequent local use of CM by oncology inpatients, ${ }^{43}$ high interest in introducing CM by the heads of the department, availability of scientific data on integrative oncology, ${ }^{44}$ and financial support from a foundation. This project is close to the cooptative model proposed by Lim et al. ${ }^{45}$ An increasing number of scientific publications have discussed theoretical and/or practical models to implement CM in a hospital or health system. $1,27,41,45,46$ These models must be adapted to the local context and situation in the country, the existing mainstream health system, and the services already proposed. The choice of model will have a strong influence on integration success. ${ }^{30}$

\section{Limitations}

There are several limitations to this project. First, it was conducted in one center only, although we believe that it is the first to survey all department heads within a single academic hospital. Second, the recommendation might not be applicable to other settings because some specificities of the studied hospital could differ from others. and the Swiss constitution has stated since 2009 that CMs should be taken into consideration.

\section{Conclusions}

This project highlighted the heterogeneity of CM practices when coordination is absent, with a variety of training for CM practitioners and for implementation of projects, leading to a lack of continuity of care within a single hospital. Thus, assessing needs regarding CM practices within a hospital is a useful step to enhance the coordination of care. Furthermore, interdepartmental CM clinical services could help to maintain and develop adequate coordination of care in the long term.

\section{Acknowledgments}

The authors thank Chantal Montreuil $(\mathrm{MScN})$ for her contribution to the project. This project was internally funded.

\section{Author Disclosure Statement}

The authors are or have been salaried by Lausanne University Hospital and the University of Fribourg; all authors declare that they have no competing interest and did not receive any specific funding for this work.

\section{References}

1. Coulter I, Ellison M, Hilton L, Rhodes H, Ryan G. Hospital-based integrative medicine: A case study of the barriers and factors facilitating the creation of a centre. Santa Monica, CA: Rand Corporation, 2008.

2. Hollenberg DB, Tsasis P, Kelley N. CAM in Canadian hospitals: The new frontier? J Complement Integr Med 2011;8. DOI: 10.2202/1553-3840.1466.

3. Lim E, Vardy JL, Oh B, et al. Integration of complementary and alternative medicine into cancer-specific supportive care programs in Australia: A scoping study. Asia Pac J Clin Oncol 2017;13:6-12.

4. Salomonsen LJ, Skovgaard L, la Cour S, et al. Use of complementary and alternative medicine at Norwegian and Danish hospitals. BMC Complement Altern Med 2011;11:4.

5. Romeyke T, Stummer H. Evidence-based complementary and alternative medicine in inpatient care: Take a look at Europe. J Evid Based Complementary Altern Med 2015;20:87-93.

6. Widmer M, Dönges $\mathrm{A}$, Wapf $\mathrm{V}$, et al. The supply of complementary and alternative medicine in Swiss hospitals. Forsch Komplementarmed 2006;13:356-361.

7. Carruzzo P, Graz B, Rodondi PY, et al. Offer and use of complementary and alternative medicine in hospitals of the French-speaking part of Switzerland. Swiss Med Wkly 2013;143:w13756.

8. Vickers AJ, Cronin AM, Maschino AC, et al. Acupuncture for chronic pain: Individual patient data meta-analysis. Arch Intern Med 2012;172:1444-1453.

9. Cheong KB, Zhang J-P, Huang Y, et al. The effectiveness of acupuncture in prevention and treatment of postoperative nausea and vomiting-A systematic review and metaanalysis. PLoS One 2013;8:e82474.

10. Apaydin EA, Maher AR, Shanman R, et al. A systematic review of St. John's wort for major depressive disorder. Syst Rev 2016;5:148.

11. Bauer BA, Cutshall SM, Wentworth LJ, et al. Effect of massage therapy on pain, anxiety, and tension after cardiac surgery: A randomized study. Complement Ther Clin Pract 2010;16:70-75.

12. Berger MM, Davadant $M$, Marin $C$, et al. Impact of a pain protocol including hypnosis in major burns. Burns 2010;36: 639-646.

13. Lescarbeau R, Payette M, Saint-Arnaud Y. Profession: Consultant. Boucherville, Québec: G. Morin, 2003.

14. Creswell JW, Poth CN. Qualitative inquiry and research design: Choosing among five approaches. Thousand Oaks, CA: Sage publications; 2017. 
15. Shuval J. Nurses in alternative health care: Integrating medical paradigms. Soc Sci Med (1982) 2006;63:1784-1795.

16. Vohra S, Feldman K, Johnston B, et al. Integrating complementary and alternative medicine into academic medical centers: Experience and perceptions of nine leading centers in North America. BMC Health Serv Res 2005;5:78.

17. Bernardini S, Cracolici F, Ferreri R, et al. Integration between orthodox medicine, homeopathy and acupuncture for inpatients: Three years experience in the first hospital for Integrated Medicine in Italy. J Tradit Complement Med 2015;5:234-240.

18. Nate KC, Griffin KH, Christianson JB, et al. Practitioner perspectives on delivering integrative medicine in a large, acute care hospital. Evid Based Complement Alternat Med 2015;2015:394040.

19. Gaertner K, Lüer SC, Frei-Erb M, et al. Complementary individual homeopathy in paediatric cancer care: A case series from a University Hospital, Switzerland. Complement Ther Med 2018;41:267-270.

20. Ben-Arye E, Popper-Giveon A, Samuels N, et al. Communication and integration: A qualitative analysis of perspectives among Middle Eastern oncology healthcare professionals on the integration of complementary medicine in supportive cancer care. J Cancer Res Clin Oncol 2016;142:1117-1126.

21. Ben-Arye E, Samuels N, Daher M, et al. Integrating complementary and traditional practices in middle-eastern supportive cancer care. J Natl Cancer Inst Monogr 2017;2017:lgx016.

22. Rossi E, Vita A, Baccetti S, et al. Complementary and alternative medicine for cancer patients: Results of the EPAAC survey on integrative oncology centres in Europe. Support Care Cancer 2015;23:1795-1806.

23. Rossi E, Di Stefano M, Firenzuoli F, et al. Add-on complementary medicine in cancer care: Evidence in literature and experiences of integration. Medicines (Basel) 2017;4: pii: E5.

24. Dobos GJ, Voiss P, Schwidde I, et al. Integrative oncology for breast cancer patients: Introduction of an expert-based model. BMC Cancer 2012;12:539.

25. Deng G. Integrative cancer care in a US academic cancer centre: The Memorial Sloan-Kettering Experience. Curr Oncol 2008;15 Suppl 2:s108.es168-es171.

26. Schad F, Thronicke A, Merkle A, et al. Implementation of an integrative oncological concept in the daily care of a german certified breast cancer center. Complement Med Res 2018;25:85-91.

27. Cramer H, Cohen L, Dobos G, et al. Integrative oncology: Best of both worlds-Theoretical, practical, and research issues. Evid Based Complement Alternat Med 2013;2013: 383142.

28. Griffin KH, Nate KC, Rivard RL, et al. Referrals to integrative medicine in a tertiary hospital: Findings from electronic health record data and qualitative interviews. BMJ Open 2016;6:e012006.

29. Wahner-Roedler DL, Lee MC, Chon TY, et al. Physicians' attitudes toward complementary and alternative medicine and their knowledge of specific therapies: 8-year follow-up at an academic medical center. Complement Ther Clin Pract 2014;20:54-60.

30. Mittring N, Perard M, Witt CM. Corporate culture assessments in integrative oncology: A qualitative case study of two integrative oncology centers. Evid Based Complement Alternat Med 2013;2013:316950.

31. Gray B, Orrock P. Investigation into factors influencing roles, relationships, and referrals in integrative medicine. $\mathbf{J}$ Altern Complement Med 2014;20:342-346.
32. Schiff E, Levy I, Arnon Z, et al. First, keep it safe: Integration of a complementary medicine service within a hospital. Int J Clin Pract 2018:e13082.

33. Eisenberg DM, Kaptchuk TJ, Post DE, et al. Establishing an integrative medicine program within an academic health center: Essential considerations. Acad Med 2016;91:1223-1230.

34. Grant SJ, Hunter J, Bensoussan A, et al. Guidance for establishing an integrative oncology service in the Australian healthcare setting-a discussion paper. Support Care Cancer 2018;26:471-481.

35. Leach MJ, Wiese M, Agnew T, Thakkar M. Health consumer and health provider preferences for an integrative healthcare service delivery model: A national cross-sectional study. Int J Clin Pract 2018;72:e13204.

36. National Center for Complementary and Integrative Health (NCCIH). Complementary, Alternative, or Integrative Health: What's In a Name? Online document at: https:// nccih.nih.gov/health/integrative-health, accessed December 5, 2018.

37. Witt CM. Training oncology physicians to advise their patients on complementary and integrative medicine. J Altern Complement Med 2018;24:1016-1017.

38. Zick SM, Czuhajewski C, Fouladbakhsh JM, et al. Integrative oncology scholars program: A model for integrative oncology education. J Altern Complement Med 2018;24:1018-1022.

39. Grant SJ, Hunter J, Seely D, et al. Integrative oncology: International perspectives. Integr Cancer Ther 2019;18: 1534735418823266.

40. Grant SJ, Marthick M, Lacey J. Establishing an integrative oncology service in the Australian healthcare setting-the Chris O'Brien Lifehouse Hospital experience. Supportive care in cancer 2018 [Epub ahead of print]; DOI: 10.1007/s00520-0184460-2.

41. Sundberg T, Halpin J, Warenmark A, et al. Towards a model for integrative medicine in Swedish primary care. BMC Health Serv Res 2007;7:107.

42. Stan DL, Wahner-Roedler DL, Yost KJ, et al. Absent and discordant electronic health record documentation of complementary and alternative medicine in cancer care. J Altern Complement Med 2018;24:988-995.

43. Jermini M, Dubois J, Rodondi PY, et al. Complementary medicine use during cancer treatment and potential herbdrug interactions from a cross-sectional study in an academic centre. Sci Rep 2019;9:5078.

44. Greenlee H, DuPont-Reyes MJ, Balneaves LG, et al. Clinical practice guidelines on the evidence-based use of integrative therapies during and after breast cancer treatment. CA Cancer J Clin 2017;67:194-232.

45. Lim EJ, Vardy JL, Oh BS, et al. A scoping review on models of integrative medicine: What is known from the existing literature? J Altern Complement Med 2017;23:8-17.

46. Mann D, Gaylord S, Norton S. Moving toward integrative care: Rationales, models, and steps for conventional-care providers. Complement Health Pract Rev 2004;9:155-172.

Address correspondence to:

Pierre-Yves Rodondi, MD

Institute of Family Medicine University of Fribourg Route des Arsenaux 41 Fribourg 1700 Switzerland

E-mail: pierre-yves.rodondi@unifr.ch 